\title{
Glia: an emerging target for neurological disease therapy
}

Akshata A Almad and Nicholas J Maragakis*

\begin{abstract}
Therapeutic strategies using stem cells for treating neurological diseases are receiving more attention as the scientific community appreciates cell-autonomous contributions to several diseases of the central nervous system. The transplantation of stem cells from various sources is now being employed for both neuronal and glial replacement. This review provides an assessment of glial contributions to some of the central nervous system diseases and the advancements in cellular replacement approaches. The rationale for glial replacement in individual diseases and the potential hurdles for cell-replacement strategies are also emphasized. The significant progress in the field of stem cell biology with the advent of tools such as induced pluripotent stem cells and imaging techniques holds promise for the clinical application of cell therapeutics.
\end{abstract}

\section{Introduction}

Rudolf Virchow first introduced the term glia (glue) in 1895 as the connective tissue supporting neurons. Four major subtypes of glial cells have since been discovered: astrocytes, oligodendrocytes, microglia and nerve glial antigen 2 (NG2) cells [1]. While diverse subpopulations of each of these glial cell types have been investigated, for the purpose of this review we will discuss how astrocytes, oligodendrocytes and NG2 cells can be used as potential therapeutic targets for cell replacement strategies.

\section{Astrocytes}

Astrocytes are stellate cells abundant in both the gray matter and white matter of the central nervous system (CNS). The historical view of astrocytes as support cells for neurons is now evolving to include functions from homeostasis to gliotransmission as reviewed by Seifert and colleagues [2].

*Correspondence: nmaraga1@jhmi.edu

Department of Neurology, Johns Hopkins University, Baltimore, MD 21205, USA
Astrocytes harbor a variety of different receptors and transporters that help mediate their primary function of homeostasis. Some of the key receptors on the astrocyte surface are the inward-rectifying $\mathrm{K}^{+}$channel [3] and aquaporin-4 receptor [4], which regulate potassium levels and osmotic changes, respectively. Some of the key transporters on astrocytes are glucose transporters (glucose transporter 1) [5] and the glutamate transporters glutamate aspartate transporter (GLAST) and glutamate transporter 1 (GLT-1) [6]. Astrocytes are interconnected via gap junctions. Calcium waves propagate between astrocytes through these gap junctions, which can further regulate the vesicular release of neurotransmitters (such as glutamate, ATP and serine) from astrocytes. This process is referred to as gliotransmission and can be a critical regulator of synaptic inputs in neurons [7].

Considering the repertoire of channels and transporters present on astrocytes and their proximity to the neurovascular unit, it is easy to appreciate that the loss of any of these functions can lead to cellular dysfunction.

\section{Oligodendrocytes}

Oligodendrocytes are the myelinating cells of the CNS present in white matter (classic oligodendrocytes) and in gray matter (satellite oligodendrocytes). Myelination is the central role of oligodendrocytes and myelin serves to maintain efficient nerve conduction, regulate axon caliber, and promote axon survival (extensively discussed by Baumann and Pham-Dinh [8]). Satellite oligodendrocytes are perineuronal and are believed to regulate the local neuronal microenvironment. Current research efforts exploring neuron-glia interactions indicate a mutually beneficial relationship in which oligodendrocytes provide structural and neurotrophic support for neurons, and in turn neurons/axons induce maturation of oligodendrocytes. Novel roles of oligodendrocytes in neuroprotection, synaptic tuning, and higher cognitive functions in addition to their traditional roles in myelination are now being explored (as reviewed by Nave [9]).

\section{Nerve glial antigen 2 cells}

Recent fate-mapping studies confirm that NG2 cells are precursors of mature oligodendrocytes and co-localize 
with the oligodendrocyte precursor cell (OPC) marker platelet-derived growth factor- $\alpha$ receptor [10-12]. However, the NG2 proteoglycan is also expressed on other cell types including macrophages and vascular mural pericytes [13]. NG2 cells constitute the highest proportion of dividing cells in the normal adult CNS [14] and in diseases including spinal cord injury [15] and amyotrophic lateral sclerosis (ALS) [10], among others. Besides its function as a progenitor cell, NG2 cells express ion channels and conduct electrical currents $[1,16,17]$. The ability of NG2 cells to self-propagate and then differentiate into oligodendrocytes makes them a potentially appealing cellular therapy for demyelinating diseases.

\section{New perspective: glial therapy}

Recent advances in the field of neuroscience are creating a holistic picture of CNS circuitry involving not just neurons, but also surrounding glial cells. The passive role of glial cells described in the past century is now overlaid with discoveries of crucial glial functions for normal CNS homeostasis [1]. This advance has shifted the focus in neuroscience from a neuron-centric to a glial-inclusive viewpoint [18].

This view allows for cell-replacement strategies to be designed around not just neuronal replacement but also glial cell replacement. For example, therapeutic strategies for spinal cord injury have evolved from attempts to conserve neurons and axons to now additionally safeguarding oligodendrocytes that could remyelinate and help preserve surviving axons. Notable work from Smith and colleagues shows that nerve conduction can be restored through remyelination [19]. Preventing demyelination has thus now become an acceptable therapeutic target. Clinical trials for spinal cord injury [20] involving the transplantation of oligodendrocyte precursor cells exemplifies the fast pace of glial replacement as a therapeutic approach $[20,21]$. Neuronal replacement may be a daunting task involving transplantation, neuronal survival, integration, and ultimately the formation of the right connections with target cells/ tissues. Glial replacement strategies promote the protection of existing host neuronal populations. This will be the central theme of the review discussing contributions of astrocytes, oligodendrocytes and NG2 cells to neurological diseases.

\section{Leukodystrophies}

Leukodystrophies are a group of diseases caused by genetic mutations resulting in abnormalities in myelin production or maintenance. Leukodystrophies can arise from a variety of gene mutations, including genes encoding myelin proteins, enzymes involved in fatty acid metabolism, lysosomal proteins, peroxisomal proteins and other as yet unknown causes [22].
Pelizaues-Merzbacher disease (PMD) is a rare leukodystrophy with a mutation in the proteolipid protein 1 gene, a major component of myelin protein [23]. Animal models with mutations in myelin genes such as shiverer mice (shi) have been used to study PMD [24]. Shi mice are homozygous recessive for the myelin basic protein gene and die at 20 to 22 weeks due to abnormal oligodendrocyte formation and lack of myelination [25]. Because these animals lack functioning oligodendrocytes, cellular replacement strategies to form new oligodendrocytes are being used as a therapy in PMD models. One source for stem cells is neural stem cells (NSCs), multipotent stem cells arising from the neuroepithelium that can differentiate into neurons, oligodendrocytes and astrocytes. Elegant transplantation studies with mouse NSCs in shi mice at birth show promising results for survival and widespread distribution of transplanted cells. Approximately $40 \%$ of transplanted NSCs differentiate into mature oligodendrocytes, replacing lost oligodendrocytes and remyelinating brains of shi mice [26]. Another study tested oligodendrocyte replacement with transplantation of OPCs, which are committed to differentiate into cells of glial lineage. Transplantation of OPCs derived from adult and fetal human brain generated oligodendrocytes and new myelin successfully [27]. Surprisingly, adult OPCs are better at generating oligodendrocytes and more efficient at myelinating axons while fetal OPCs give rise to a substantial astrocyte population in addition to oligodendrocytes. These successful transplantation studies have progressed to human clinical trials for PMD with a phase I safety and preliminary efficacy trial for intracerebral transplantation of human stem cells [28].

Alexander's disease is a rare disorder with an astrocyte abnormality due to mutations in the gene for the intermediate filament glial fibrillary acidic protein [29]. This abnormality results in demyelination and the formation of Rosenthal fibers - proteinaceous inclusions in astrocytes. Although treatment for Alexander's disease using gene therapy is being tested, cellular replacement therapy has not yet been pursued and might make an excellent alternative approach [30]. Targeting disorders with cell-specific mutations in either oligodendrocytes or astrocytes may thus be approached using diverse therapeutic strategies, including substituting missing metabolic enzymes, overexpressing proteins of interest or glial cell transplantation biology.

\section{Demyelinating diseases: multiple sclerosis}

Multiple sclerosis (MS) is a chronic inflammatory disease characterized by infiltration of immune cells in the CNS resulting in demyelinated lesions and denuded axons. A number of animal models have been developed to study MS [31], such as experimental autoimmune 
encephalomyelitis (EAE) in which a myelin antigen or T cells raised against myelin are used to elicit an immune response that destroys myelin [32]. While EAE is the most common MS model used, Theiler's murine virus and toxin models such as lysolecithin [33] and cuprizone [34] are also used to study demyelination. The loss of myelin in MS affects the integrity of axons, leading to their degeneration and dysfunction. Although the local lesion environment mounts a response to restore myelin via the formation of new myelin sheaths, this process of remyelination is ineffective either due to the extent of demyelination or to recurring demyelination.

The therapeutic goal for demyelination in MS is to enhance formation of new oligodendrocytes and subsequently new myelin. This entails developmental events akin to recruitment of OPCs to sites of demyelination, proliferation of OPCs, and further cues to induce differentiation of OPCs into oligodendrocytes. Several seminal papers reported a plethora of factors needed for every step that eventually forms new myelin sheaths, as reviewed by Franklin as well as Miller [31,35]. MS researchers believe one significant therapeutic hurdle is the recruitment of OPCs to the site of demyelination [31]. The lack of migration cues, extracellular matrix molecules, or accumulation of inhibitory molecules could be some of the factors affecting recruitment of OPCs to demyelinating plaques.

The transplantation of rodent neural precursor/stem cells in an experimental EAE model resulted in successful integration and differentiation of NSCs into oligodendrocytes, remyelination, and functional recovery in animals. This led to similar studies with human fetal NSCs in a nonhuman primate model of MS serving as a steppingstone to preclinical trials [36]. The limited sources for neural precursor cells (NPCs) have directed researchers to embryonic stem cells (ESCs), which are pluripotent selfrenewing cells capable of giving rise to all three germ layers [37]. ESCs can serve as a source for making NSCs in large proportions for transplantation studies. However, as newer methods for the generation of stem cells from other tissues are developed, the use of ESCs will probably become less important as a source of stem cells for therapeutics.

Even though cellular replacement of oligodendrocytes has been tested successfully in animal models, there is a dearth of matching clinical data in MS. One complication could be the immunosuppression regimen for MS patients who already have heightened immune responses. Additionally, even if the transplants survive and integrate around demyelinating areas, a paucity of differentiation factors or increased inhibitors of differentiation may render the transplants of no value. A combinatorial approach of pharmacological, immunological, and cellbased therapy may therefore be the way to pursue clinical trials.

\section{Neurodegenerative diseases Alzheimer's disease}

Alzheimer's disease (AD) is a neurodegenerative disease that manifests as progressive memory loss and dementia. One of the pathological hallmarks of $\mathrm{AD}$ is the accumulation of extracellular plaques made of $\beta$-amyloid $(A \beta)$ proteins leading to toxicity and death of neurons [38]. Evidence from postmortem tissue of $\mathrm{AD}$ patients and $\mathrm{AD}$ animal models suggests that, in addition to neurons, astrocytes also harbor the $A \beta$ plaques [39]. In fact, it is suggested that apolipoprotein $E$ receptors on the astrocytic surface transport the extracellular $\mathrm{A} \beta$ protein, degrade the toxic plaques, and confer neuroprotection [40]. Astrocytes can also exert neuroprotection by inhibiting the toxic production of nitric oxide from microglial cells [41].

However, the inability to degrade continuing accumulation of $A \beta$ makes astrocytes aberrant and neurotoxic. Hyperactive astrocytes begin secreting proinflammatory cytokines including IL- $1 \beta$ and TNF $\alpha$, which in turn activate microglia and result in neuronal damage [42]. Furthermore, internalization of $A \beta$ proteins compromises the homeostatic functions of astrocytes such as counteracting increased oxidative stress in $\mathrm{AD}$ brains and recycling of extracellular glutamate, as reports suggest the loss of the major astrocytic glutamate transporter GLT-1 in brain samples from AD patients [43].

One approach has been to transplant astrocytes that can conduct normal functions and replace aberrant astrocytes. Pihlaja and colleagues tested this hypothesis and transplanted adult and neonatal GFP-expressing astrocytes in the hippocampi of $\mathrm{AD}$ mice expressing human $A \beta$ [44]. Transplanted astrocytes were able to internalize the $A \beta$ plaques and clear up to $70 \%$ of the plaques via upregulation of proteolytic enzymes [45]. These findings were observed as early as 1 week after transplantation. However, approximately $45 \%$ of the transplanted astrocytes were lost at 2 months. This loss was primarily associated with increased microglial activation and phagocytosis after astrocyte transplantation.

Besides astrocytic changes, imaging and histopathological studies reveal demyelination and loss of oligodendrocytes in $\mathrm{AD}$ patients and animal models [46]. Oligodendrocytes are fairly new participants in $\mathrm{AD}$ pathology, and studies delineating their loss have attributed it to collateral damage from plaque formation, a lack of calcium homeostasis, oxidative stress and the proinflammatory environment in AD. Further studies addressing the potential of oligodendrocyte replacement using oligodendrocyte lineage cells as a therapeutic tool may be a future line of investigation.

\section{Amyotrophic lateral sclerosis}

ALS is a motor neuron disease with progressive muscle atrophy and paralysis due to loss of cortical, hindbrain 
and spinal cord motor neurons. Recent advances in the field focus on glial contributions to disease etiology. Transgenic mice $(\mathrm{Tg})$ overexpressing the human mutant superoxide dismutase 1 (SOD1) protein are used frequently as ALS models mimicking the progressive motor weakness characteristic of the disease. Specifically, deleting human SOD1 mutation in astrocytes using the Cre recombinase system demonstrates amelioration of disease in these transgenic mice, suggesting that SOD1 mutations in astrocytes contribute to disease $[47,48]$. We have shown in a focal transplantation model that astrocytes mediate toxicity with transplantation of human mutant SOD1 glial-restricted precursor (GRP)-derived astrocytes in the cervical spinal cord of healthy wild-type animals, resulting in a striking loss of motor neurons along with functional deficits in the animal [49]. Importantly, in vitro co-culture studies identified that astrocytes derived from postmortem ALS patients caused significant toxicity and demise of wild-type motor neurons compared with astrocytes from control patients [50]. All of the above studies suggest the critical involvement of astrocytes in the ALS pathobiology.

Given these findings, targeting astrocytes may become a potential ALS treatment strategy by modulating astrocyte-specific proteins or by conferring neuroprotection through astrocyte transplantation to replace diseased astrocytes. For the latter, transplantation of rodent GRPs in an ALS rat model showed efficient migration, integration and differentiation of GRPs into mature astrocytes [51]. These transplanted cells increased survival of motor neurons and lifespan in $\mathrm{Tg}$ human mutant SOD1 rats. The decreased GLT-1 levels in the spinal cord of the Tg human mutant SOD1 animals were partially restored, thereby imparting neuroprotection. Similarly when human GRPs were transplanted into the spinal cord of $\mathrm{Tg}$ human mutant SOD1 mice, the cells survived, integrated and differentiated into astrocytes in the diseased animals [52]. Unlike rodent GRPs, however, human GRP-derived astrocytes did not provide significant neuroprotection. Despite this lack of neuroprotection, this study demonstrated the safety and feasibility of human GRPs in making astrocytes in an in vivo environment. Currently, transplantation of human spinal cord-derived neural stem cells is underway in a phase I trial for ALS patients with the goal of sequestering excess glutamate and secreting neuroprotective trophic factors - possibly through the differentiation of these cells into astrocytes [53].

In addition to astrogliosis, Kang and colleagues recently described a profound increase in the proliferative response of NG2 cells in the Tg human mutant SOD1 mice [10]. Myelin loss in ALS patients has been reported but the role of myelin and oligodendrocyte loss in ALS is not well established. Whether NG2 cell proliferation plays a role in ALS onset or progression is under investigation.

\section{Parkinson's disease}

Parkinson's disease (PD) is a movement disorder characterized by bradykinesia, rest tremors, rigidity of movement, and postural instability due to loss of dopaminergic neurons in the substantia nigra [54]. Histological examination of PD brains reveals the presence of Lewy bodies, which are $\alpha$-synuclein protein inclusions in neurons. Lewy bodies have also been found in astrocytes and oligodendrocytes in sporadic PD patients $[54,55]$. This finding has given rise to the noncell autonomous hypothesis of PD pathogenesis, where glial cells in addition to neurons may contribute to disease initiation and spread - similar to hypotheses for AD and ALS. To understand how the presence of $\alpha$-synuclein in astrocytes contributes to disease, a recent study engineered a conditional mouse overexpressing $\alpha$-synuclein in astrocytes [56]. These animals displayed profuse neuronal loss in the substantia nigra and spinal cord along with progressive paralysis and decreased lifespan. These mice had hypertrophic astrocytes dysfunctional in glutamate uptake. The presence of $\alpha$-synuclein in astrocytes also elicited microglial activation and neuronal death.

Another theory is that decreased glutathione levels in astrocytes result in their inability to counteract increased oxidative stress in PD brains and makes neurons vulnerable. In a neurotoxin (1-methyl-4-phenyl-1,2,3,6-tetrahydropyridine (MPTP)) model of PD, astrocytic overexpression of Nrf2, a transcription factor encoding antioxidant enzymes, was found to be neuroprotective [57]. Astrocytes also secrete growth factors such as glial cell-derived neurotrophic factor, brain-derived neurotrophic factor and nerve growth factor, among others. Several groups have illustrated neuroprotection and behavioral recovery by the transplantation of rodent astrocytes overexpressing glial cell-derived neurotrophic factor, brain-derived neurotrophic factor and nerve growth factor via viral vectors in a MPTP/6-hydroxydopamine neurotoxin model of PD $[58,59]$. These studies show a causal link between diseased astrocytes in PD that are incapable of conducting their normal trophic and protective functions, resulting in neuron loss. Seminal work by Svendsen and colleagues showed that when human fetal-derived NPCs were transplanted in a 6-hydroxydopamine model of PD, the graft cells survived and gave rise to fully differentiated astrocytes at 20 weeks post transplantation [60]. However, the growing literature of human fetal ESC and NPC transplantation generating dopaminergic neurons has sidelined glial-specific cellular therapeutics. Since clinical studies with human ESCs/ NPCs have resulted in variable outcomes, efforts are underway to increase the efficiency of dopaminergic 
neuron generation and produce astrocytes with elevated levels of growth factors to safeguard the endogenous neuronal population.

In continuing efforts to derive astrocytes, researchers have resorted to mesenchymal tissue as a source of glial cells. Bahat-Stroomza and colleagues used human adult bone-marrow-derived stromal cells and differentiated them into astrocyte-like cells in vitro [61]. When these cells were transplanted in a Parkinson's MPTP rodent model, animals receiving transplants preserved more dopaminergic neurons and showed improved behavioral outcomes compared with saline controls. While the authors show that stromal-derived astrocyte-like cells secrete neuroprotective growth factors, it will be important to establish whether transplantation of control cells such as fibroblasts would achieve similar outcomes instead of the saline controls used in the study.

Oligodendroglial contributions to PD are not well established. Interestingly, oligodendrocytes co-localize with $\alpha$-synuclein in PD and multiple system atrophy patient samples. Similarly, oligodendrocyte death was noted acutely in a MPTP model of PD [62] and overexpression of $\alpha$-synuclein in oligodendrocytes resulted in extensive neurodegeneration in the neocortical and nigrostriatal region [63]. These early studies open an underexplored research area in PD, and continuing efforts will tell whether oligodendrocytes are important contributors to the disease.

\section{Transplantation: risks and benefits}

The clinical applicability of cell therapeutics has yet to realize any standard for the treatment of nervous system disorders. The enthusiasm for the potential of stem cell transplantation has grabbed the attention of the popular press but numerous scientific hurdles are currently being navigated to establish these cell transplantation paradigms as mainstream CNS treatment approaches. The fascinating results from transplantation studies in animal models often lead to expedited clinical trials resulting in unanticipated and confounding outcomes. In transplantation therapy, therefore, decisions about the most appropriate cell type for transplantation, the route of delivery, the dosing, site and timing of transplantation, and safety must be carefully examined and executed.

The type or source of cell being utilized - whether ESC, NSC, GRP/OPC or of non-CNS source such as mesenchymal and bone-marrow-derived stem cells - probably needs to be tailored to the disease target. For example, while fetal OPCs are considered more pliable and migratory in nature compared with adult OPCs, transplantation studies in shi mice show efficient oligodendrocyte formation and myelination with adult OPCs [64]. The use of less differentiated cells such as ESCs or more differentiated cells such as NSCs or GRPs should be bolstered with evidence from animal studies and further preclinical studies. Clinicians and researchers will need to pursue rigorous measures regarding the safety, dosing and reproducibility of studies with transplanted cells.

One of the most significant clinical concerns is the potential for stem cells to either have ectopic engraftment into regions outside the CNS or the risk of uninhibited cell division and subsequent tumor formation. Promising methodologies for tracking transplanted cells using noninvasive imaging techniques (magnetic resonance imaging, positron emission tomography and bioluminescence) could potentially help to monitor the migration patterns of transplanted cells $[65,66]$.

The fate of the transplanted cells may also be affected by the surrounding milieu. For example, autopsy results from a PD patient transplanted with human NSCs show Lewy body accumulation in transplanted cells in addition to host cells [67].

One major issue in transplantation studies has been the possibility of immune rejection of nonautologous transplant sources. A potential alternative to this dilemma is the use of induced pluripotent stem cells (iPSCs) - adult somatic cells reprogrammed to revert to a pluripotent state [68]. iPSCs could overcome concerns of immune rejection as well as reduce the ethical issues concerning use of human embryonic cells. That said, future studies will determine whether patient-derived iPSCs will retain the genetic profile of their endogenous diseased cells, necessitating ex vivo genetic correction before reintroducing the cells. iPSC technology also empowers scientists to directly study properties of patient-derived cells and serves as a model system for drug development strategies. However, the details of iPSC characterization and utilization in cellular therapeutics are beyond the scope of this review.

\section{Conclusion and future directions}

Cellular replacement therapy is a milestone in the field of neuroscience with a promising future in replacing lost cells and also creating an environment conducive to neuronal survival through release of trophic factors and immunomodulatory molecules. Since the discovery of iPSCs [69], progress has been made in generating human iPSC lines from a number of CNS disorders. A recent study discusses transplantation of iPSC-derived NPCs from a PD patient in a primate model taking iPSC research to preclinical stages [70]. Krencik and colleagues reported a pioneering method of deriving astrocytes from iPSCs, which, along with astrocyte lineage markers, displayed functional properties of glutamate uptake, synaptogenesis and propagation of calcium waves [71]. This protocol can now be utilized for deriving glial cells from diseased iPSC lines, paving a path for future glial therapies. In addition to the diseases mentioned here, 
glial contributions in several other neurological diseases such as stroke, ischemia, spinal cord injury, schizophrenia, depression, autism, and others are being explored. The ongoing efforts in recognizing glial contributions to diseases and the efforts to replace/replenish them make glial cells a potentially valuable therapeutic target for cell replacement strategies.

This article is part of a thematic series on Clinical applications of stem cells edited by Mahendra Rao. Other articles in the series can be found online at http://stemcellres.com/series/clinical

\section{Abbreviations}

$A \beta, \beta$-amyloid; AD, Alzheimer's disease; ALS, amyotrophic lateral sclerosis; CNS, central nervous system; $E A E$, experimental autoimmune encephalomyelitis; ESC, embryonic stem cell; GFP, green fluorescent protein; GRP, glial-restricted precursor cell; GLT-1, glutamate transporter 1; IL, interleukin; iPSC, induced pluripotent stem cell; MPTP, 1-methyl-4-phenyl-1,2,3,6-tetrahydropyridine; MS, multiple sclerosis; NG2, nerve glial antigen 2; Nrf2, nuclear factor (erythroid-derived 2)-like 2; NPC, neural precursor cell; NSC, neural stem cell; OPC, oligodendrocyte precursor cell; PD, Parkinson's disease; PMD, PelizauesMerzbacher disease; shi, shiverer mice; SOD1, superoxide dismutase 1; Tg, transgenic mice; TNF, tumor necrosis factor.

\section{Competing interests}

NJM is an unpaid scientific advisor to Q Therapeutics, Inc. AAA declares that he has no competing interests.

Published: 28 September 2012

\section{References}

1. Verkhratsky AN, Butt A: Glial Neurobiology: A Textbook. Chichester, UK: John Wiley \& Sons; 2007:xiv.

2. Seifert G, Schilling K, Steinhauser C: Astrocyte dysfunction in neurological disorders: a molecular perspective. Nat Rev Neurosci 2006, 7:194-206.

3. Higashi K, Fujita A, Inanobe A, Tanemoto M, Doi K, Kubo T, Kurachi Y: An inwardly rectifying $\mathrm{K}(+)$ channel, Kir4.1, expressed in astrocytes surrounds synapses and blood vessels in brain. Am J Physiol Cell Physio/ 2001, 281:C922-C931.

4. Nielsen S, Nagelhus EA, Amiry-Moghaddam M, Bourque C, Agre P, Ottersen OP: Specialized membrane domains for water transport in glial cells: highresolution immunogold cytochemistry of aquaporin-4 in rat brain. J Neurosci 1997, 17:171-180

5. Morgello S, Uson RR, Schwartz EJ, Haber RS: The human blood-brain barrier glucose transporter (GLUT1) is a glucose transporter of gray matter astrocytes. Glia 1995, 14:43-54.

6. Rothstein JD, Martin L, Levey Al, Dykes-Hoberg M, Jin L, Wu D, Nash N, Kuncl RW: Localization of neuronal and glial glutamate transporters. Neuron 1994, 13:713-725.

7. Parpura V, Heneka MT, Montana V, Oliet SH, Schousboe A, Haydon PG, Stout RF Jr, Spray DC, Reichenbach A, Pannicke T, Pekny M, Pekna M, Zorec R, Verkhratsky A: Glial cells in (patho)physiology. J Neurochem 2012, 121:4-27.

8. Baumann N, Pham-Dinh D: Biology of oligodendrocyte and myelin in the mammalian central nervous system. Physiol Rev 2001, 81:871-927.

9. Nave KA: Myelination and the trophic support of long axons. Nat Rev Neurosci 2010, 11:275-283.

10. Kang SH, Fukaya M, Yang JK, Rothstein JD, Bergles DE: NG2+ CNS glial progenitors remain committed to the oligodendrocyte lineage in postnatal life and following neurodegeneration. Neuron 2010, 68:668-681.

11. Rivers LE, Young KM, Rizzi M, Jamen F, Psachoulia K, Wade A, Kessaris N, Richardson WD: PDGFRA/NG2 glia generate myelinating oligodendrocytes and piriform projection neurons in adult mice. NatNeurosci 2008 , 11:1392-1401

12. Zhu X, Bergles DE, Nishiyama A: NG2 cells generate both oligodendrocytes and gray matter astrocytes. Development 2008, 135:145-157.

13. Nishiyama A: Polydendrocytes: NG2 cells with many roles in development and repair of the CNS. Neuroscientist 2007, 13:62-76.
14. Horner PJ, Power AE, Kempermann G, Kuhn HG, Palmer TD, Winkler J, Thal LJ, Gage FH: Proliferation and differentiation of progenitor cells throughout the intact adult rat spinal cord. J Neurosci 2000, 20:2218-2228.

15. McTigue DM, Wei P, Stokes BT: Proliferation of NG2-positive cells and altered oligodendrocyte numbers in the contused rat spinal cord J Neurosci 2001, 21:3392-3400.

16. Chittajallu R, Aguirre A, Gallo V: NG2-positive cells in the mouse white and grey matter display distinct physiological properties. J Physio/ 2004, 561:109-122.

17. Karadottir R, Hamilton NB, Bakiri Y, Attwell D: Spiking and nonspiking classes of oligodendrocyte precursor glia in CNS white matter. Nat Neurosci 2008, 11:450-456.

18. Barres BA: The mystery and magic of glia: a perspective on their roles in health and disease. Neuron 2008, 60:430-440.

19. Smith EJ, Blakemore WF, McDonald WI: Central remyelination restores secure conduction. Nature 1979, 280:395-396.

20. Safety Study of GRNOPC1 in Spinal Cord Injury [http://clinicaltrials.gov/ct2/ show/NCT01217008?term $=$ geron\&recr=Open\&rank=5]

21. Davies SJ, Shih CH, Noble M, Mayer-Proschel M, Davies JE, Proschel C: Transplantation of specific human astrocytes promotes functional recovery after spinal cord injury. PLoS One 2011, 6:e17328.

22. Goldman SA, Schanz S, Windrem MS: Stem cell-based strategies for treating pediatric disorders of myelin. Hum Mol Genet 2008, 17:R76-R83.

23. Saugier-Veber P, Munnich A, Bonneau D, Rozet JM, Le Merrer M, Gil R, Boespflug-Tanguy O: X-linked spastic paraplegia and PelizaeusMerzbacher disease are allelic disorders at the proteolipid protein locus. Nat Genet 1994, 6:257-262.

24. Kondo Y, Duncan ID: Transplantation of oligodendrocyte progenitor cells in animal models of leukodystrophies. Methods Mol Biol 2009, 549:175-185.

25. Chernoff GF: Shiverer: an autosomal recessive mutant mouse with myelin deficiency. J Hered 1981, 72:128.

26. Yandava BD, Billinghurst LL, Snyder EY: 'Global' cell replacement is feasible via neural stem cell transplantation: evidence from the dysmyelinated shiverer mouse brain. Proc Natl Acad Sci U S A 1999, 96:7029-7034.

27. Windrem MS, Nunes MC, Rashbaum WK, Schwartz TH, Goodman RA, McKhann G, Roy NS, Goldman SA: Fetal and adult human oligodendrocyte progenitor cell isolates myelinate the congenitally dysmyelinated brain. Nat Med 2004, 10:93-97.

28. Safety Study of Human CNS Stem Cells Transplantation in Patients with Pelizaeus-Merzbacher Disease [http://clinicaltrials.gov/ct2/show/ NCT01005004?term=pmd\&rank=1]

29. Brenner M, Johnson AB, Boespflug-Tanguy O, Rodriguez D, Goldman JE, Messing A: Mutations in GFAP, encoding glial fibrillary acidic protein, are associated with Alexander disease. Nat Genet 2001, 27:117-120.

30. Kemp K, Mallam E, Scolding N, Wilkins A: Stem cells in genetic myelin disorders. Regen Med 2010, 5:425-439.

31. Franklin RJ: Why does remyelination fail in multiple sclerosis? Nat Rev Neurosci 2002, 3:705-714.

32. Johns TG, Kerlero de Rosbo N, Menon KK, Abo S, Gonzales MF, Bernard CC: Myelin oligodendrocyte glycoprotein induces a demyelinating encephalomyelitis resembling multiple sclerosis. J Immuno/ 1995, 154:5536-5541.

33. Kotter MR, Zhao C, van Rooijen N, Franklin RJ: Macrophage-depletion induced impairment of experimental CNS remyelination is associated with a reduced oligodendrocyte progenitor cell response and altered growth factor expression. Neurobiol Dis 2005, 18:166-175.

34. Shen S, Sandoval J, Swiss VA, Li J, Dupree J, Franklin RJ, Casaccia-Bonnefil P: Age-dependent epigenetic control of differentiation inhibitors is critical for remyelination efficiency. Nat Neurosci 2008, 11:1024-1034.

35. Miller RH: Oligodendrocyte origins. Trends Neurosci 1996, 19:92-96.

36. Pluchino S, Gritti A, Blezer E, Amadio S, Brambilla E, Borsellino G, Cossetti C, Del Carro U, Comi G, 't Hart B, Vescovi A, Martino G: Human neural stem cells ameliorate autoimmune encephalomyelitis in non-human primates. Ann Neurol 2009, 66:343-354.

37. Svendsen CN, Smith AG: New prospects for human stem-cell therapy in the nervous system. Trends Neurosci 1999, 22:357-364.

38. Austin J, Trueb L, Hutchison J, Rinehart R, Miles B: Isolation and preliminary characterization of Alzheimer plaques from pre-senile and senile dementia. J Neuropathol Exp Neurol 1971, 30:146.

39. Nagele RG, D'Andrea MR, Lee H, Venkataraman V, Wang HY: Astrocytes accumulate $A$ beta 42 and give rise to astrocytic amyloid plaques in 
Alzheimer disease brains. Brain Res 2003, 971:197-209.

40. Koistinaho M, Lin S, Wu X, Esterman M, Koger D, Hanson J, Higgs R, Liu F, Malkani S, Bales KR, Paul SM: Apolipoprotein E promotes astrocyte colocalization and degradation of deposited amyloid-beta peptides. Nat Med 2004, 10:719-726.

41. Vincent VA, Tilders FJ, Van Dam AM: Inhibition of endotoxin-induced nitric oxide synthase production in microglial cells by the presence of astroglial cells: a role for transforming growth factor beta. Glia 1997, 19:190-198.

42. Johnstone M, Gearing AJ, Miller KM: A central role for astrocytes in the inflammatory response to beta-amyloid; chemokines, cytokines and reactive oxygen species are produced. J Neuroimmunol 1999, 93:182-193.

43. Tian G, Kong Q, Lai L, Ray-Chaudhury A, Lin CL: Increased expression of cholesterol 24S-hydroxylase results in disruption of glial glutamate transporter EAAT2 association with lipid rafts: a potential role in Alzheimer's disease. J Neurochem 2010, 113:978-989.

44. Pihlaja R, Koistinaho J, Malm T, Sikkila H, Vainio S, Koistinaho M: Transplanted astrocytes internalize deposited beta-amyloid peptides in a transgenic mouse model of Alzheimer's disease. Glia 2008, 56:154-163.

45. Pihlaja R, Koistinaho J, Kauppinen R, Sandholm J, Tanila H, Koistinaho M: Multiple cellular and molecular mechanisms are involved in human $A \beta$ clearance by transplanted adult astrocytes. Glia 2011, 59:1643-1657.

46. Desai MK, Mastrangelo MA, Ryan DA, Sudol KL, Narrow WC, Bowers WJ: Early oligodendrocyte/myelin pathology in Alzheimer's disease mice constitutes a novel therapeutic target. Am J Pathol 2010, 177:1422-1435.

47. Yamanaka K, Chun SJ, Boillee S, Fujimori-Tonou N, Yamashita H, Gutmann DH, Takahashi R, Misawa H, Cleveland DW: Astrocytes as determinants of disease progression in inherited amyotrophic lateral sclerosis. Nat Neurosci 2008, 11:251-253.

48. Wang L, Gutmann DH, Roos RP: Astrocyte loss of mutant SOD1 delays ALS disease onset and progression in G85R transgenic mice. Hum Mol Genet 2011, 20:286-293.

49. Papadeas ST, Kraig SE, O'Banion C, Lepore AC, Maragakis NJ: Astrocytes carrying the superoxide dismutase 1 (SOD1G93A) mutation induce wildtype motor neuron degeneration in vivo. Proc Natl Acad Sci U S A 2011 108:17803-17808

50. Haidet-Phillips AM, Hester ME, Miranda CJ, Meyer K, Braun L, Frakes A, Song S, Likhite S, Murtha MJ, Foust KD, Rao M, Eagle A, Kammesheidt A, Christensen A, Mendell JR, Burghes AH, Kaspar BK: Astrocytes from familial and sporadic ALS patients are toxic to motor neurons. Nat Biotechno/ 2011, 29:824-828.

51. Lepore AC, Rauck B, Dejea C, Pardo AC, Rao MS, Rothstein JD, Maragakis NJ: Focal transplantation-based astrocyte replacement is neuroprotective in a model of motor neuron disease. Nat Neurosci 2008, 11:1294-1301.

52. Lepore AC, O'Donnell J, Kim AS, Williams T, Tuteja A, Rao MS, Kelley LL, Campanelli JT, Maragakis NJ: Human glial-restricted progenitor transplantation into cervical spinal cord of the SOD1 mouse model of ALS. Plos One 2011, 6:e25968.

53. Human Spinal Cord Derived Neural Stem Cell Transplantation for the Treatment of Amyotrophic Lateral Sclerosis [http://clinicaltrials.gov/ct2/ show/NCT01348451?term=als\&rank=5]

54. Halliday GM, Stevens CH: Glia: initiators and progressors of pathology in Parkinson's disease. Mov Disord 2011, 26:6-17.

55. Wakabayashi K, Hayashi S, Yoshimoto M, Kudo H, Takahashi H: NACP/asynuclein-positive filamentous inclusions in astrocytes and oligodendrocytes of Parkinson's disease brains. Acta Neuropathol 2000, 99:14-20.

56. Gu XL, Long CX, Sun L, Xie C, Lin X, Cai H: Astrocytic expression of Parkinson's disease-related A53T a-synuclein causes neurodegeneration in mice. Mol Brain 2010, 3:12.
57. Chen PC, Vargas MR, Pani AK, Smeyne RJ, Johnson DA, Kan YW, Johnson JA: Nrf2-mediated neuroprotection in the MPTP mouse model of Parkinson's disease: critical role for the astrocyte. Proc Natl Acad Sci U S A 2009, 106:2933-2938.

58. Lin LF, Doherty DH, Lile JD, Bektesh S, Collins F: GDNF: a glial cell linederived neurotrophic factor for midbrain dopaminergic neurons. Science 1993, 260:1130-1132.

59. Grothe C, Timmer M: The physiological and pharmacological role of basic fibroblast growth factor in the dopaminergic nigrostriatal system. Brain Res Rev 2007, 54:80-91.

60. Svendsen CN, Caldwell MA, Shen J, ter Borg MG, Rosser AE, Tyers P, Karmiol S, Dunnett SB: Long-term survival of human central nervous system progenitor cells transplanted into a rat model of Parkinson's disease. Exp Neurol 1997, 148:135-146.

61. Bahat-Stroomza M, Barhum Y, Levy YS, Karpov O, Bulvik S, Melamed E, Offen D: Induction of adult human bone marrow mesenchymal stromal cells into functional astrocyte-like cells: potential for restorative treatment in Parkinson's disease. J Mol Neurosci 2009, 39:199-210.

62. Takagi S, Hayakawa N, Kimoto H, Kato H, Araki T: Damage to oligodendrocytes in the striatum after MPTP neurotoxicity in mice. J Neural Transm 2007, 114:1553-1557.

63. Ubhi K, Rockenstein E, Mante M, Inglis C, Adame A, Patrick C, Whitney K, Masliah E: Neurodegeneration in a transgenic mouse model of multiple system atrophy is associated with altered expression of oligodendroglialderived neurotrophic factors. J Neurosci 2010, 30:6236-6246.

64. Windrem MS, Nunes MC, Rashbaum WK, Schwartz TH, Goodman RA, McKhann G, 2nd, Roy NS, Goldman SA: Fetal and adult human oligodendrocyte progenitor cell isolates myelinate the congenitally dysmyelinated brain. Nat Med 2004, 10:93-97.

65. Sykova E, Jendelova P: Migration, fate and in vivo imaging of adult stem cells in the CNS. Cell Death Differ 2007, 14:1336-1342.

66. Politi LS: MR-based imaging of neural stem cells. Neuroradiology 2007, 49:523-534.

67. Kordower JH, Chu Y, Hauser RA, Freeman TB, Olanow CW: Lewy body-like pathology in long-term embryonic nigral transplants in Parkinson's disease. Nat Med 2008, 14:504-506.

68. Takahashi K, Yamanaka S: Induction of pluripotent stem cells from mouse embryonic and adult fibroblast cultures by defined factors. Cell 2006, 126:663-676.

69. Yu J, Vodyanik MA, Smuga-Otto K, Antosiewicz-Bourget J, Frane JL, Tian S, Nie J, Jonsdottir GA, Ruotti V, Stewart R, Slukvin II, Thomson JA: Induced pluripotent stem cell lines derived from human somatic cells. Science 2007, 318:1917-1920.

70. Kikuchi T, Morizane A, Doi D, Onoe H, Hayashi T, Kawasaki T, Saiki H, Miyamoto S, Takahashi J: Survival of human induced pluripotent stem cell-derived midbrain dopaminergic neurons in the brain of a primate model of parkinson's disease. J Parkinson's Dis / 2011, 1:395-412.

71. Krencik R, Weick JP, Liu Y, Zhang ZJ, Zhang SC: Specification of transplantable astroglial subtypes from human pluripotent stem cells. Nat Biotechnol 2011, 29:528-534

doi:10.1186/scrt128

Cite this article as: Almad AA, Maragakis NJ: Glia: an emerging target for neurological disease therapy. Stem Cell Research \& Therapy 2012, 3:37. 